\title{
An investigation on printability of different solvent based inks by gravure printing onto various substrates
}

\section{ABSTRACT}

Gravure printing is an intaglio printing process, the image to be printed is engraved on the surface of the gravure cylinder, so that the image to be printed is embedded into the surface. The places engraved in the cylinder during printing are filled with ink, surplus of ink is stripped by a blade and separated for reuse. Print quality consistency and efficiency is high in gravure printing. It is also possible to print on different substrates. Ink systems, viscosity, surface properties of substrate material and dot structures on the gravure cylinder are the main factors that determine the print quality. Appropriate inks can be chosen depending on the material to be printed and finished product used area. Mostly solvent based inks are used. The aim of this study is to determine the solvent that can enable higher quality printing on different substrates, which are frequently used in the gravure printing system, and to investigate the conditions under which the ink-substrates interface relationship can be the best in terms of printability. In this study, IGT F1 laboratory type gravure testing machine was used. Polyethylene and polypropylene printable films are used as the substrate materials. Three different solvent-based inks are used, prepared with ethyl alcohol, ethyl acetate and isopropyl alcohol. Density, contact angle, surface energy and gloss properties of the printed materials were examined. The printability properties of selected substrates and inks have been determined.

\author{
Arif Ozcan ${ }^{1}$ \\ Rasim Zulfigaroglu ${ }^{2}$ \\ ${ }^{1}$ Marmara University, School of \\ Applied Sciences, Department \\ of Printing Technologies, \\ Istanbul - Turkey \\ ${ }^{2}$ Marmara University, Institute \\ of Pure and Applied Sciences, \\ Department of Printing \\ Technologies, Istanbul - Turkey
}

Corresponding author: Arif Ozcan e-mail:arifozcan@marmara.edu.tr

First recieved: 06.04.2020. Accepted: 02.06.2020.

\section{KEY WORDS}

Gravure printing, printability, solvent based inks, surface energy

\section{Introduction}

Gravure printing is an intaglio printing process, the image to be printed is engraved on the surface of the gravure cylinder, so that the image to be printed is embedded into the surface. The places engraved in the cylinder during printing are filled with ink, surplus of ink is stripped by a blade and separated for reuse (Figure 1).

The image areas to be printed consist of honeycomb shaped cells or wells that are engraved into a copper cylinder. When the substrate material touches the gravure cylinder, the ink on the roller is transferred to the material and printing takes place (Gillett, 2003). The next step is the drying of the ink. Shortly, printing takes place this way.

As seen in the figure, the components of the printing system are the tank where the liquid ink is held, the engraving roller as a printing plate, the blade that is used to scrape the surplus ink, and the impression cylinder that enables the substrate material to take the ink from engraving roller. The primary function of the impression cylinder is to ensure that the substrate material is in adequate contact with the ink in the cells, ensuring the correct ink transfer from the engraving cylinder. The cylinder is typically steel coated with rubber or similar compatible material (Simseker, Kurt \& Arman, 2012). 


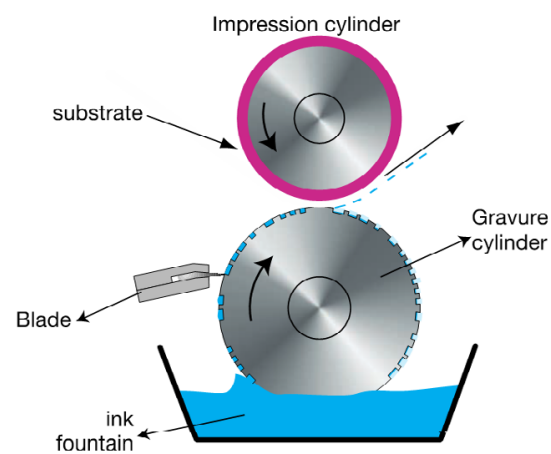

» Figure 1: Schematic diagram of gravure printing (Kipphan, 2001)

As the pressure in the impression cylinder increases, the contact area in the gravure cylinder and the pressure between the substrate material and the impression cylinder also increase. This contact area is referred to as the printing nip (Gillett, 2003). The purpose of doctor blade is to remove surplus ink from the engraving roller (Elsayad et al, 2002). The blade is generally a thin, flexible material made of steel or, in some cases, plastic. In general, the doctor blade moves in and out along the length of the gravure cylinder as it rotates. In this way, undesired particles or surplus inks are prevented from remaining under the doctor blade. The pressure adjustment should be done well with the gravure cylinder so that the doctor blade can scrape the ink properly (Neff, 2009).

Today, its use as rotogravure printing is common. It is basically the same as its working principle. Gravure printing is at the forefront with its high quality prints and high circulation prints in conventional printing systems (Lee, Mun \& Yoo,2009). Print quality consistency and efficiency is high in gravure printing. It is also possible to print on different substrates. Ink systems, viscosity, surface properties of substrate material and dot structures on the gravure cylinder are the main factors that determine the print quality (Tora \& Sharma, 2016).

Gravure printing is a sophisticated system. It is possible to print on numerous materials with gravure printing, however, widely prints on metallized films and plastic films (PE, PP, OPP, BOPP, PVC) (Goyat, Singh \& Sharma, 2018). In general, the three main products and product groups printed with gravure printing are as follows;

- Publication

- Magazines, retail inserts, and catalogs

- Packaging

- Folding cartons, flexible packaging, and labels

- Product

- End-use items: Floor coverings, gift wrap, and wallpaper

Gravure printing in all these products and product groups guarantees consistently high print quality, even on low-quality paper and other substrates. However, due to the preparation cost of the engraving cylinder, it is preferred for high circulation prints rather than low circulation prints to lower the average unit cost. The most important feature that limits gravure printing is the cylinder preparation cost (Gamota et al, 2013).

It is only possible to print on different materials with gravure printing processes by choosing the appropriate ink for the material. Appropriate inks can be chosen depending on the material to be printed, finished product used area, and even environmental awareness or human health (Nguyen et al, 2015). Gravure inks are low viscosity liquid inks that can easily hold onto the engraved cells in the cylinder and allow them to be transferred to the substrate later. Mostly toluene based, alcohol based, water based and UV based ink options are common. Due to the increasing environmental and human health sensitivity in recent years, the use of water based ink is expected to increase (Park et al, 2015).

The image is created on the surface of the gravure cylinder by processing the gravure printing system. After the cylinder is supplied as a steel raw material, copper coating is made in several grades in order to process the surface. For image formation; the image to be printed with the digital engraving system (engraving) method is sent from the computer to the engraving machine (Joshi \& Bandyopadhyay, 2014). The laser processing head moves in and out on the cylinder and renders the image to form dots (Figure 2).

In the processing head of the machine, there are the diamond tip for processing the image and the auxiliary cleaning tip, cutter tip, absorbent tip. According to the image data received from that machine, diamond tip opens dots on the surface of the copper on the cylinder. After the image is processed on the cylinder surface, its surface is covered with chrome so that it can print. After the cylinder surface processes are completed, proof is taken, and any errors are detected (Figure 3). The depths and width of the cells vary based on the amount of ink required to obtain the desired ink density and color in the printed image.

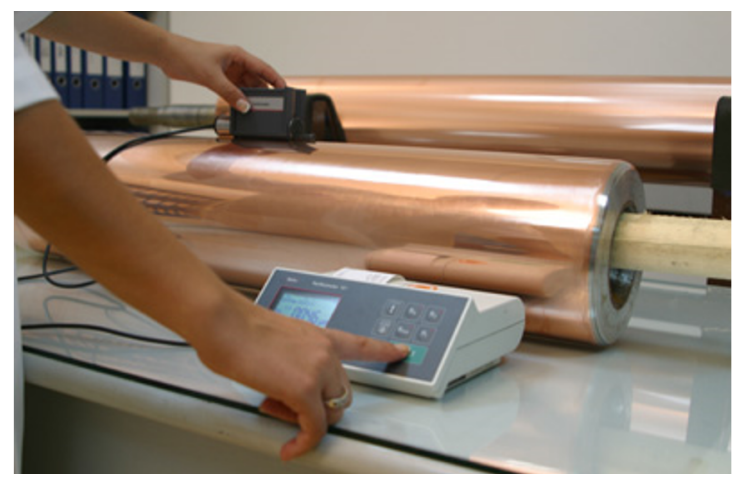

» Figure 2: Gravure cylinder engraving 


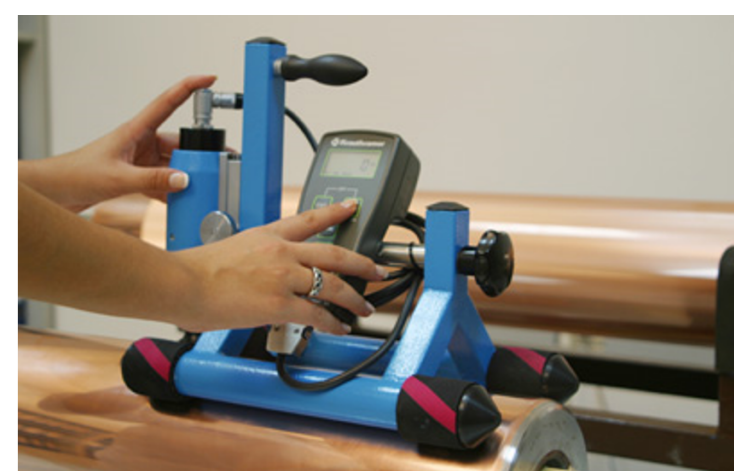

» Figure 3: Gravure printing proofing process

In this study, prints were made with inks prepared with three different solvents on two different printing materials and the effects of variables on printability were examined.

\section{Materials and Methods}

\section{Material}

The raw materials (binders, dyestuff additives) for the inks to be prepared in the study were obtained from

Table 1

Ink formulation

\begin{tabular}{c|c}
\hline Component & Percentage (\%) \\
\hline Resin & 40 \\
\hline Cyan dye stuff & 20 \\
\hline Additive & 5 \\
\hline Solvent & 35 \\
\hline
\end{tabular}

Siegwerg (Turkey). The polyethylene and polypropylene printing substrate used were obtained from a local manufacturer. All solvents used in ink dilution are of analytical purity and were purchased from Sigma Aldrich (Turkey).

\section{Method}

The cyan inks used in the study were prepared according to Table 1 under laboratory conditions.

In ink preparation, dyestuff, resin, different additives are weighed and mixed in a mechanical mixer at $1000 \mathrm{rpm}$. The viscosities of the inks obtained were adjusted with their own solvent for 20 seconds with a ford cup. The solvent type of the inks obtained is shown in Table 2.

Depending on the properties of the solvent, the amount of solvent in each ink varies, which changes the pigment concentration. The properties of the solvents are given in Table 3.

With the produced inks, gravure test prints were made on the surface of Polypropylene and Polyethylene films with IGT F1. The film specifications are given Table 4. The gravure printing plate is IGT F1 gravure plate (402:153:432). Printing parameters; 250 $\mathrm{N}$ printing pressure and $0.1 \mathrm{~m} / \mathrm{s}$ printing speed.

Table 2

Solvent type ink name relationship

\begin{tabular}{c|c}
\hline Ink Type & Solvent Type \\
\hline F1 & Ethyl Alcohol \\
\hline F2 & Ethyl Acetate \\
\hline F3 & Isopropyl Alcohol \\
\hline
\end{tabular}

\section{Table 3}

Used solvents and properties

\begin{tabular}{c|c|c|c|c}
\hline Solvent Type & Boiling Point $\left({ }^{\circ} \mathbf{C}\right)$ & $\begin{array}{c}\text { Evaporation rate } \\
(\mathbf{B u ~} \mathbf{A c}=\mathbf{1 0})\end{array}$ & Flash point $\left({ }^{\circ} \mathbf{C}\right)$ & Density at $\mathbf{4}\left({ }^{\circ} \mathbf{C}\right)$ \\
\hline Ethyl Alcohol & 81 & 33 & 13.9 & 0.79 \\
\hline Ethyl Acetate & 77 & 62 & -5 & 0.9 \\
\hline Isopropyl Alcohol & 82.3 & 29 & 11.7 & 0.78 \\
\hline
\end{tabular}

\section{Table 4}

Polymeric films specifications

\begin{tabular}{c|c|c|c|c|c|c|c|c}
\hline & $\begin{array}{c}\text { Moisture } \\
\text { permeability } \\
\mathbf{g} / \mathbf{m}^{2} / \text { day }\end{array}$ & $\begin{array}{c}\text { The O2 } \\
\text { permeability } \\
\mathbf{c m}^{\mathbf{3} / \mathbf{m}^{2} / \text { day }}\end{array}$ & $\begin{array}{c}\text { Operating } \\
\text { temperature } \\
\text { range }{ }^{\circ} \mathbf{C}\end{array}$ & $\begin{array}{c}\text { Enthalpy } \\
\mathbf{J} / \mathbf{g}\end{array}$ & $\begin{array}{c}\text { Glass } \\
\text { transition } \\
\text { temperature } \\
{ }^{\circ} \mathbf{C}\end{array}$ & $\begin{array}{c}\text { Thermal } \\
\text { decomposition }{ }^{\circ} \mathbf{C}\end{array}$ & $\begin{array}{c}\text { Specific } \\
\text { gravity } \mathbf{g} / \mathbf{c m}^{\mathbf{3}}\end{array}$ & $\begin{array}{c}\text { Surface } \\
\text { Energy } \mathbf{~ m N / m}\end{array}$ \\
\hline $\mathrm{PE}$ & 20 & 6500 & $-50 / 80$ & 70 & -80 & 475 & 0,910 & 31 \\
\hline $\mathrm{PP}$ & 6 & 2250 & $-18 / 135$ & 90 & -20 & 460 & 0,905 & 29 \\
\hline
\end{tabular}


The wettability of polymeric films was determined using the contact angle with the sessile water droplet method. The characteristics of surfaces were determined with contact angle (TAPPI T 458). Distilled water was used as standard wetting fluid in a Pocket Goniometer Model PG-X, (FIBRO Systems AB, Sweden), which was measured as a function of time. The program is of version 3.4. Images of water droplets were then recorded by using a $C C D$ video camera. Surface energies were calculated on the contact angle by ASTM D5946 standard test method.

The color and density measurements of the prints on different substrates were made by CIE L*a*b* method using $X$-Rite eXact portable spectrophotometer according to ISO 12647-2:2013 standard (Tutak, Beytut \& Ozcan, 2018). The measurement conditions of the spectrophotometer are determined as polarization filter with $0^{\circ} / 45^{\circ}$ geometry with 2 observer angle with D50 light source in the range of 400-700 $\mathrm{nm}$. The difference between the colors of the different prints was calculated according to formula 1 according to the CIE $\triangle$ E 2000 ISO 13655 standard.

$\Delta E_{00}=\sqrt{\left(\frac{\Delta L^{\prime}}{k_{L} S_{L}}\right)^{2}+\left(\frac{\Delta C^{\prime}}{k_{C} S_{C}}\right)^{2}+\left(\frac{\Delta H^{\prime}}{k_{H} S_{H}}\right)^{2}+R_{T} \frac{\Delta C^{\prime}}{k_{C} S_{C}} \frac{\Delta H^{\prime}}{k_{H} S_{H}}}$

The gloss measurements of prints were carried out with BYK Gardner GmbH micro Tri-gloss $60^{\circ}$ geometry in accordance with ISO 2813:2014.

\section{Results}

Contact angle and surface energies of polyethylene and polypropylene printable films are measured and given in Figure 4 in order to determine the printability properties of the substrates to be used.

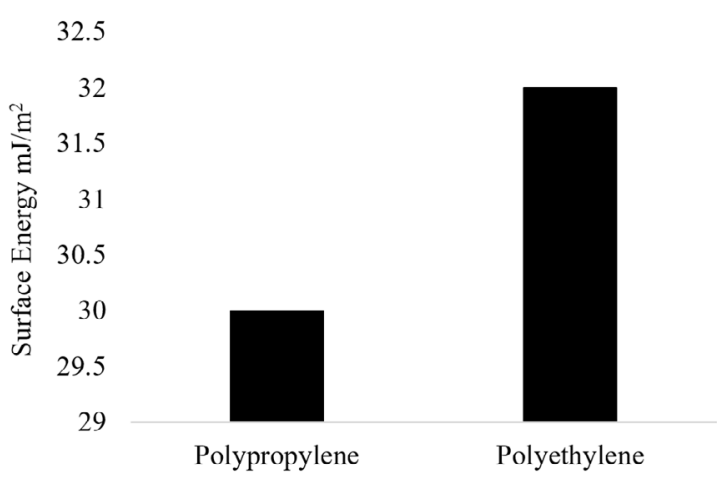

Printing Substrate Type

» Figure 4: Surface energies of printing substrate

When Figure 4 is examined, it is seen that the surface energy of polypropylene is smaller than polyethylene. The small surface energy indicates that it is easier to print on the paper with solvent based inks. In order to be able to print on a surface, there must be at least
$10 \mathrm{~mJ} / \mathrm{m}^{2}$ difference between the surface energy of the substrate material and the surface energy of the ink. It has been concluded that the printing material with the lowest surface energy is the polypropylene and the printability is better than polyethylene. The results are compatible with the literature (Lindner et al, 2018). The contact angle and surface energy are inversely proportional. This is an expected result and is compatible with the literature (Ozcan et al, 2019).

Gravure test prints were successfully performed with inks prepared with 3 different solvents on two different printing materials.

Printing densities for different substrates were examined. Figure 5 shows the densities of the prints made with polyethylene film with different solvent inks. When Figure 5 is examined, it is found that the print density in both alcohols has lower density in all cell depth than the ink containing ethyl acetate. This is because ethyl acetate is more volatile than alcohol in room conditions. Thus, ink containing ethyl acetate dried faster and could not find time to spread so it could not find time to grow. In this case, the amount of colorant per unit area was excessive and the density increased onto printing. When the alcohols are compared with each other, it is equal in the high cell depth but as the cell depth shrinks, the print density of the isopropyl alcohol-based ink is lowest, but the values are very close to each other and are within the standard deviation range of ISO 12647-4.

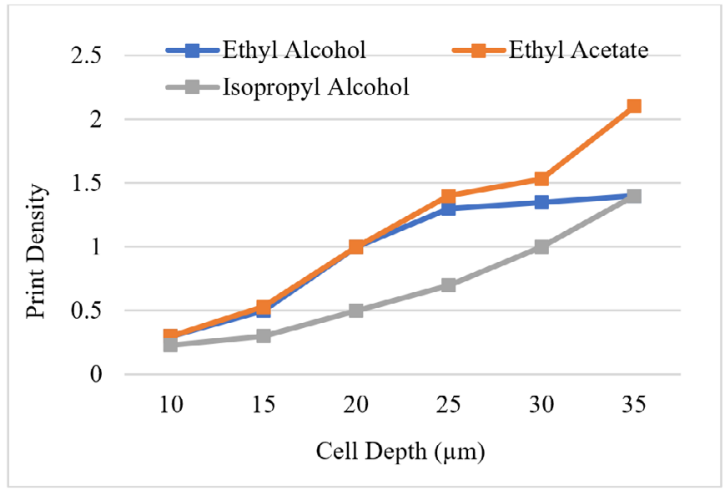

» Figure 5: Print density of polyethylene film substrate

In Figure 6, the densities of the prints made with polypropylene film with different solvent inks are shown. When Figure 6 is analyzed, it was found that the print density of both alcohols in the direction similar to polyethylene film has lower density than the ink containing ethyl acetate in all cell dept. When the alcohols are compared among themselves, the density values in all cell depth are very close to each other and in the standard deviation range of ISO 12647-4.

When two different films were compared for the same type inks, it was determined that higher print 
density was obtained in polypropylene film than polyethylene film. This result is an expected result because when the surface energies were examined, the lower surface energy of the polypropylene film provided a better bonding surface for the inks and the density, one of the printability values, increased.

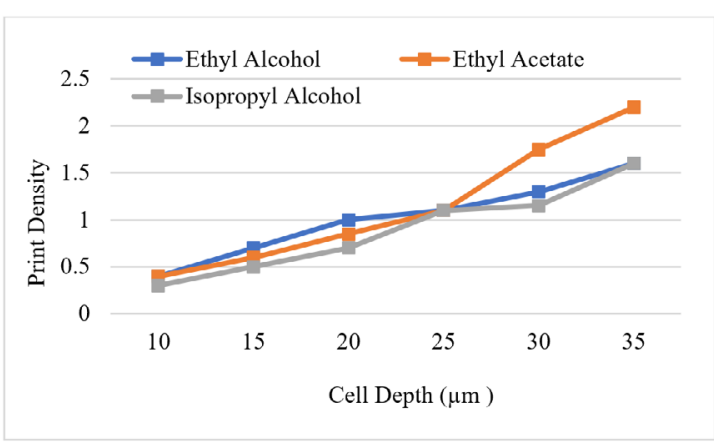

» Figure 6: Print density of polypropylene film substrate

The growth of the dot in prints varies depending on the drying time of the ink. The tone values of the prints on polyethylene and polypropylene films were measured and the values in Figure 7 were obtained. When Figure 7 is examined, it is determined that the change of the points of ethyl alcohol and isopropyl alcohol are similar. The evaporation of alcohols in close periods explains this result. However, the printed dot areas of the ethyl acetate in printing remained lower than the alcohols. Because while the ink dries, the dot did not grow large enough and the ink spread less than it should be.

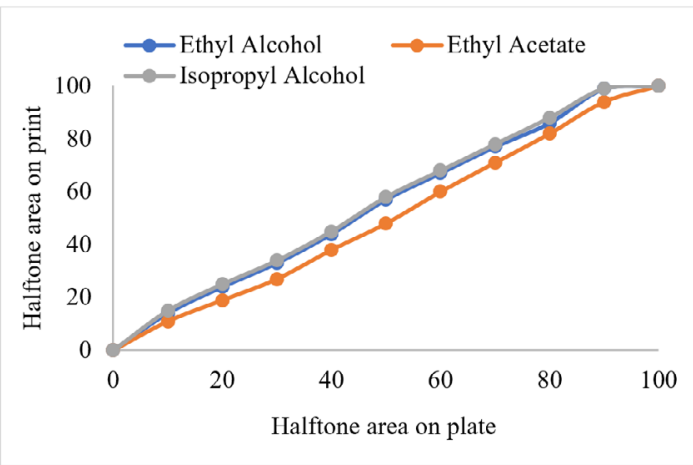

» Figure 7: Halftone values prints

Color and gloss values of the prints are given in Table 5 . When Table 5 is examined, it is determined that the darkest color in both printing materials is the ink prepared with ethyl acetate. Since the ink could not spread too much, the amount of pigment in the unit area was high, so the color became darker and the color difference of these inks was higher than $\Delta \mathrm{E}$ of other ink prints. Ethyl alcohol and isopropyl alcohol for both films gave similar results in color. When the obtained $\Delta \mathrm{E}$ values are examined, it has been determined that all color differences are below the range specified in ISO 12647-4 and below the range that can be perceived by the human eye
$(\Delta E=3)$ (Frimova et al, 2005). All inks obtained according to this result can be used in both substrates. When the gloss values were examined, it was determined that the highest gloss was obtained with ethyl acetate inks.

\section{Table 5}

Printability parameters of test prints

\begin{tabular}{l|c|c|c|c|c} 
& $\mathbf{L}^{*}$ & $\mathbf{a}^{*}$ & $\mathbf{b}^{*}$ & $\mathbf{\Delta E}$ & Gloss \\
\hline F1 substrate PE & 47.7 & -25.7 & -42.4 & 1.40 & 24 \\
\hline F2 substrate PE & 45.4 & -25.1 & -44.9 & 2.30 & 28 \\
\hline F3 substrate PE & 47.5 & -25.6 & -42.5 & 1.35 & 23 \\
\hline F1 substrate PP & 47.6 & -25.5 & -42.3 & 1.39 & 25 \\
\hline F2 substrate PP & 45.6 & -24.9 & -44.7 & 2.10 & 32 \\
\hline F3 substrate PP & 47.6 & -25.5 & -42.7 & 1.26 & 24 \\
\hline
\end{tabular}

Another selection parameter of the solvent to be used in ink is its prices. Figure 8 shows that the most expensive solvent is ethyl alcohol. For this reason, the use of isopropyl alcohol in real time printing is preferred to the use of ethyl alcohol because it gives very close results with isopropyl alcohol in all printability parameters. The use of ethyl acetate should be limited in gravure inks. Because the copper on the engraving cylinder, which is often exposed to ethyl acetate, corrodes after a while and the engraving cylinder is damaged.

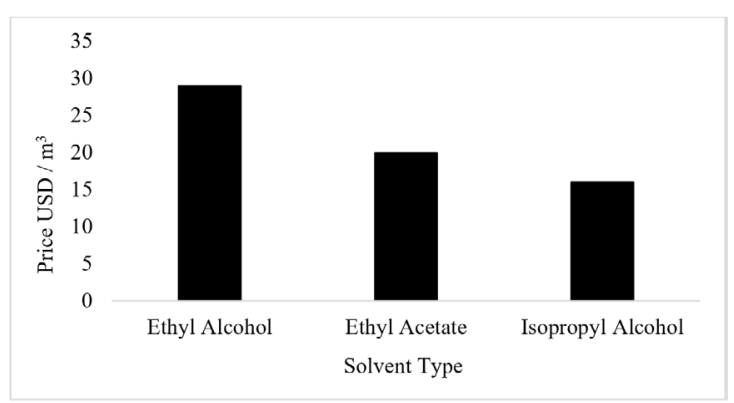

» Figure 8: Dated 28.06.2020 price values different solvents

\section{Conclusions}

In this study, prints were made with inks prepared with three different solvents on two different printing materials and the effects of variables on printability were examined. As a result, it has been concluded that the printability is better than polyethylene, since the printing substrate with the lowest surface energy is polypropylene. As ethyl acetate dries faster than other alcohol-based inks, ink density and dot growth are better in terms of printability. Ethyl acetate gave the best results in terms of color and gloss. However, it is highly corrosive to the ethyl acetate engraving cylinder. For this reason, it is not recommended to use it for a long time and in large quantities. For this reason, it is more suitable to be mixed with either isopropyl or ethyl 
alcohol. When examined in terms of price, the solvent with the lowest unit cost is isopropyl alcohol. For this reason, when it is necessary to choose among alcohols, isopropyl alcohol is a suitable solvent. As a result, it is recommended to use a mixture of ethyl acetate-isopropyl alcohol for both substrates in gravure printing.

\section{Acknowledgements}

This work has been supported by Marmara University Scientific Research Projects Coordination Unit under grant number FEN-C-YLP-080519-0164.

\section{References}

Elsayad, S., Morsy, F., El-Sherbiny, S. \& Abdou, E. (2002) Some factors affecting ink transfer in gravure printing. Pigment \& Resin Technology. 31 (4), 234-240. Available from: doi: 10.1108/03699420210432429

Frimova, A., Pekarovicova, A., Fleming, P. D. \& Pekarovic, J. (2005) Ink stability during printing. TAGA Journal. 2, 122-131.

Gamota, D. R., Brazis, P., Kalyanasundaram, K. \& Zhang, J. (eds.) (2013) Printed organic and molecular electronics. Berlin, Springer Science \& Business Media.

Gillett, K. (2003) Gravure-Process and Technology - 2nd Edition. Rochester, GAA and GEF.

Goyat, A., Singh, N. \& Sharma, S. (2018) Investigation of web-fed gravure printing for optimization of job change over time. International Journal of Engineering Sciences \& Research Technology. 7 (1), 192-195. Available from: doi: 10.5281/zenodo.1135964

Joshi, A. V. \& Bandyopadhyay, S. (2014) Effect of gravure process variables on void area in shrink film. Journal of Coatings Technology and Research. 11 (5), 757-764. Available from: doi: 10.1007/s11998-014-9581-z

Kipphan, H. (ed.) (2001) Handbook of print media: technologies and production methods. Berlin, Springer Science \& Business Media.

Lee, J. W., Mun, K. K. \& Yoo, Y. T. (2009) A comparative study on roll-to-roll gravure printing on PET and BOPP webs with aqueous ink. Progress in Organic Coatings.
64 (1), 98-108. Available from: doi: 10.1016/j.porgcoat.2008.07.011

Lindner, M., Rodler, N., Jesdinszki, M., Schmid, M. \& Sängerlaub, S. (2018) Surface energy of corona treated PP, PE and PET films, its alteration as function of storage time and the effect of various corona dosages on their bond strength after lamination. Journal of Applied Polymer Science. 135 (11), 45842. Available from: doi: 10.1002/app.45842

Neff, J. E. (2009) Investigation of the effects of process parameters on performance of gravure printed ito on flexible substrates. PhD thesis. Georgia Institute of Technology.

Nguyen, H. A. D., Lee, C., Shin, K. H. \& Lee, D. (2015) An investigation of the ink-transfer mechanism during the printing phase of high-resolution roll-to-roll gravure printing. IEEE Transactions on Components, Packaging and Manufacturing Technology. 5 (10), 1516-1524. Available from: doi: 10.1109/TCPMT.2015.2473853

Ozcan, A., Kandirmaz, E. A., Hayta, P. \& Mutlu, B. (2019) Examination of the effect of melamine as a filler in paper coatings on print quality. Cellulose Chemistry and Technology. 53 (3-4), 307-313. Available from: doi: 10.35812/CelluloseChemTechnol.2019.53.30

Park, J., Nguyen, H. A. D., Park, S., Lee, J., Kim, B. \& Lee, D. (2015) Roll-to-roll gravure printed silver patterns to guarantee printability and functionality for mass production. Current Applied Physics. 15 (3), 367-376. Available from: doi: 10.1016/j.cap.2015.01.007

Simseker, O., Kurt, B. \& Arman, E. (2012) Effects of different solvents to printability in gravure printing. Asian Journal of Chemistry. 24 (11), 5253-5256.

Tora, S. \& Sharma, S. (2016) Effect of NIP Pressure Parameters on Substrate's Surface Characteristics and Printability in Roto-Gravure Printing. International Journal of Modern Engineering \& Management Research. 4 (1), 37-41.

Tutak, D., Beytut, H. N. \& Ozcan, A. (2018) Investigation of the effects of different ink density values on color gamut in offset printing. Journal of Graphic Engineering and Design. 9 (1), 23-28. Available from: doi: 10.24867/JGED-2018-1-023

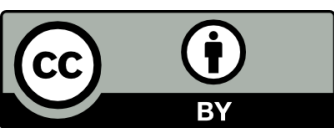

(C) 2020 Authors. Published by the University of Novi Sad, Faculty of Technical Sciences, Department of Graphic Engineering and Design. This article is an open access article distributed under the terms and conditions of the Creative Commons Attribution license 3.0 Serbia (http://creativecommons.org/licenses/by/3.0/rs/). 